Article

\title{
Smart Cities-A View of Societal Aspects
}

\author{
Vasile Baltac $(\mathbb{D}$ \\ Faculty of Public Administration, National School for Political Study and Public Administration, \\ Bucharest 012104, Romania; vasile.baltac@snspa.ro
}

Received: 23 September 2019; Accepted: 2 December 2019; Published: 9 December 2019

\begin{abstract}
Smart city projects are considered real challenges to the development of cities everywhere. The concept itself has many definitions, but a smart city should be defined less based on implemented IT solutions, and more based on optimization of its basic functions using new technologies. There are societal aspects of smart city implementations, similar to eGovernment early projects, and aspects of the use of digital technology that raise concerns. In most cities, the digital divide is still a problem. Smart city projects are the result of the fourth industrial revolution, but cities still lack a full implementation of solutions derived from previous industrial revolutions. Despite that, cities report a lot of smart city projects. Money still gets spent, as being a smart city is, in many cases, an artificial priority and a fashionable topic. Moreover, non-Internet technologies and their relations to a good smart city solution are also not considered. Digital divide bridging is one requirement for a full implementation of a smart city concept. A review of acceleration and deceleration factors shows the obstacles faced by smart city projects. Rankings of cities based on several smart city criteria are published frequently. Various approaches lead to contradictory rankings. A new set of comprehensive rankings developed by an international organization and based on reputable reports and statistics would be useful. The study is based on several smart city and eGovernment projects in Romania.
\end{abstract}

Keywords: smart city; digital access; digital affordability; digital content; user eSkills; smart city rankings

\section{Introduction}

Cities play a paramount role in social life. This role determines the actions to create smart cities. The smart city is a concept that may be defined in many ways; one of them is related to the use of digital technologies and all its functions. Despite numerous opinions defining smart cities based on the degree of IT implementation, this paper considers a smart city defined less based on these implemented IT solutions and more on the optimization of its functions through IT.

The smart city concept is a subset of the eGovernment concept and should inherit from it the citizen-centric principle. It also inherits one of the challenges of eGovernment early implementations-the lack of enough planning and resource wastage when smart city projects are approached more for their fashionable nature and less for their real needs. This is frequently a case in areas where the digital divide is present, both from the citizen's side and the side of the city administration staff.

The smart city projects are results of the fourth industrial revolution or the cyber physical revolution. However, many cities still lack full implementation of solutions of the previous industrial revolutions, mainly regarding city planning and transportation networks. What Schwab [1] fears may apply to smart city implementations as well—organizations that are unable to adapt, and city governments that could fail to employ and regulate new technologies to capture their benefits, resulting in growth of inequality. 
In this paper, the concept of the smart city is reviewed and its relation to digital technologies is evaluated. The impact of the digital divide on smart cities' implementations, their acceleration and deceleration factors, and benchmarking are taken into consideration as societal problems.

\section{Smart City Concept}

Smart city definitions are mostly related to the use of digital technologies in all their functions. One such definition is as follows [2]:

"A Smart city is an urban area that uses different types of electronic Internet of things (IoT) sensors to collect data and then use these data to manage assets and resources efficiently. This includes data collected from citizens, devices, and assets that is processed and analysed to monitor and manage traffic and transportation systems, power plants, water supply networks, waste management, crime detection, information systems, schools, libraries, hospitals, and other community services".

The definition provided is in agreement with many others that mostly cover technical matters related to the last digital revolution. However, many authors think that a smart city goes further optimizing its functions for the benefit of the citizen. In agreement with such authors [3-5], we could consider that a smart city is a city that has smart governance, smart economy, smart mobility, smart environment, smart people, and smart living (Figure 1).

This implies that a smart city has a complete range of eGovernment services and a solid IT infrastructure, and practices open government (smart governance); moreover its economy is run with eBusiness and eCommerce support, its logistic and transport activities are run and optimized with IT support, it has large databases (smart mobility), it largely uses renewable energy, has IT controlled energy networks and green buildings and controls pollution and water and air quality (smart environment); in addition, under such a system, people have digital competences at a sufficient level, access to education and training, access to data bases (smart people), the lifestyle is influenced by IT, and there is highly developed health and housing services, cultural services, and social cohesion (smart living).

There has been a lot of interest recently around the topic of smart cities. Google searches of "smart city" and "smart cities" return more than 4 million results. Google Trends confirms an increasing interest in the topic in the last five years. Figure 2 shows the search trends on the topic of smart city between July 2009 and July 2019. Google Scholar also returns 2.4 million papers and books for smart city [6]. There are many papers and implementation reports that raise concerns over its social aspects. One of them is the significant wastage of resources for early smart city projects based on a limited IT infrastructure and in cities plagued by digital divide [7].

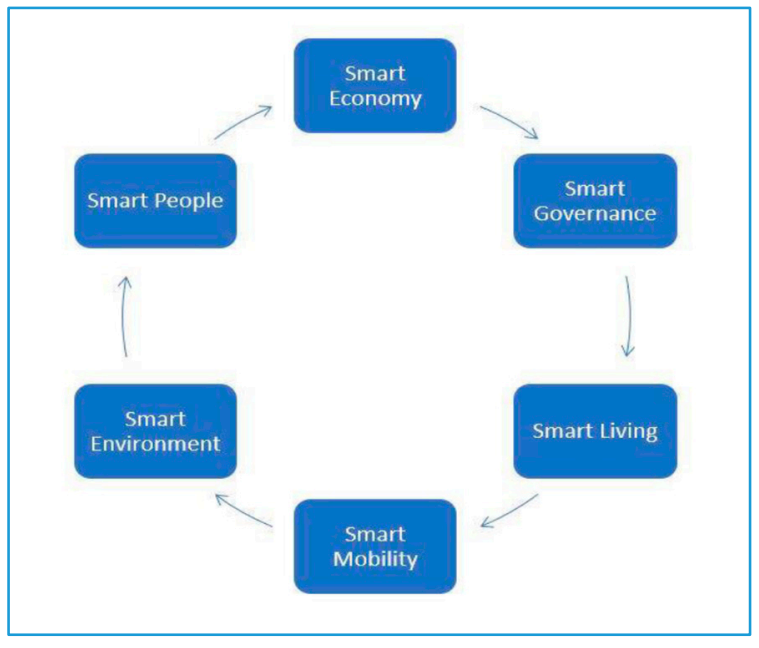

Figure 1. Smart city components. 


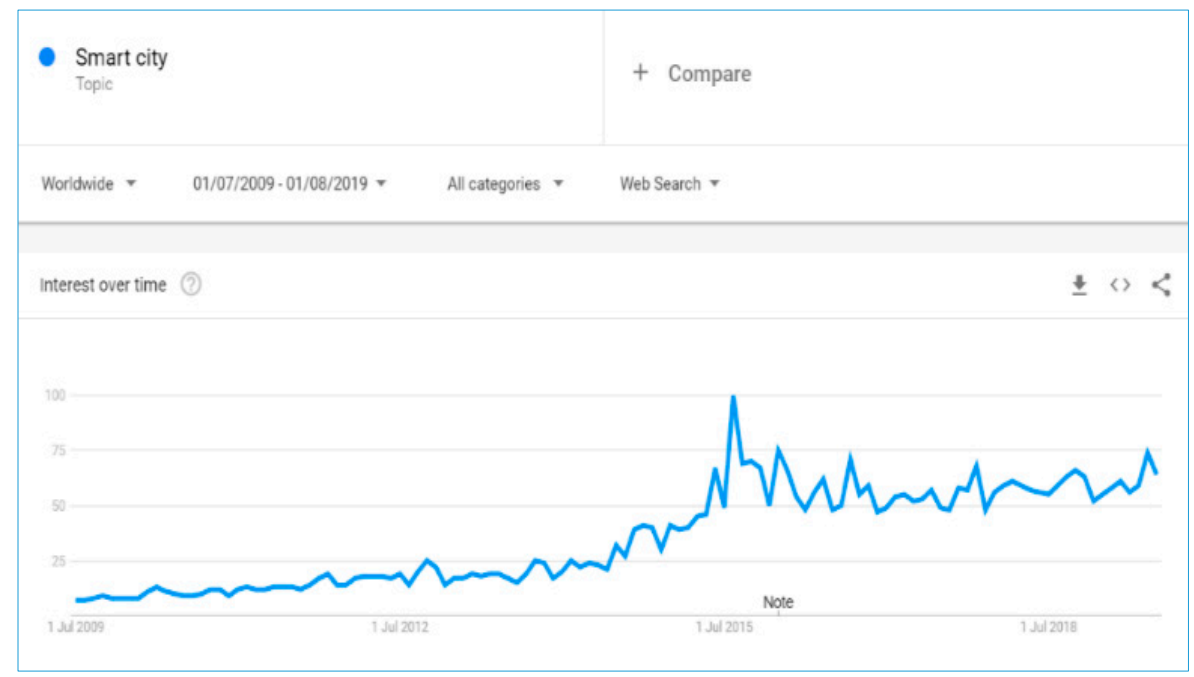

Figure 2. Searches for Smart City between 2009 and 2019 (Google Trends).

\section{Smart Cities and Digital Technologies}

It is largely accepted that the concept of smart city is closely related to digital technology. The abovementioned definition by Wikipedia [2] strongly points to the role of IoT devices in a smart city. A smart city uses all definitory means of the cyber physical revolution-mobile devices and their apps, cloud computing, big data, artificial intelligence, IoT, etc. Some of them are easier to implement, as in the case of IoT, mobile devices, and even the cloud. Others have more complex implementations as is the case of big data and artificial intelligence, which require big investments and specific training of city administration staff. One application of artificial intelligence, face recognition, stirs controversy, as seen in a recent incident that took place in San Francisco, California [8].

There are aspects of digital technology use in smart cities that raise concerns. Many are due to problems generated during implementation, in a way similar to the ones encountered during eGovernment implementations.

Such a problem is the lack of adaptation of city structures to the potential of new technologies. Old, less-optimized structures are impregnated with digital devices and applications. This has an adverse effect, and in many cases, these devices and applications are not accepted as a natural development but as an added feature, after being rejected in the first place as a "foreign body". An example of this is an excessively early tax office application [7]. The user interface is quite bureaucratic and consisted of " $n$ " desks to be visited. After informatization, it had " $n$ " people with " $n$ " networked desktops all accessing the same database.

This is seen in many smart city projects-the lack of city process restructuring before the implementation of smart city solutions. It is obvious that it is important to finalize the impact of previous industrial revolutions on the city, and in many cases, the impact of the first one-the industrial revolution of steam and manufacturing. The use of steam power radically changed cities by bringing people and goods to these cities by railways. Stations were built mostly on a radial structure, with every station linking a certain direction. Most big cities have linked their railway stations directly by rail, such as in Brussels, Belgium, or by urban mass transportation, such as in London, UK. Others, such as Bucharest, Romania, still lack such links. Most cities in the world are suffocated by traffic. Although solutions such as road rings, urban highways, park and ride, roundabouts, etc. exist, they are not the subject of this paper. Factories were built in what was, in the 19th and 20th centuries, city outskirts. Now, they are replaced by new offices or residential buildings or commercial centers. Rarely is this accompanied by serious city planning, thus creating new traffic problems.

IoT and other digital technologies are applied to such old structures that are not quite updated. The result is a minor improvement, or sometimes no improvement at all, especially regarding Smart mobility. 
Of all the digital technologies, the mobile phone has had the biggest impact. Citizens already possess more mobiles than desktops. The number of mobiles (smartphones and tablets) is bigger than the number of inhabitants in most cities. It is therefore important to implement smart city applications, while keeping in mind that citizens will access them mainly on mobile devices. However, this is not always the case.

Other factors to be considered are the volatility of solutions and the speed of implementation. The high rate of innovation in the digital world is a fact. Many devices and applications have been put on the market in the last 10-15 years. This is too short a time for city planning. A relevant example is communications. 3G technology was introduced in 2001 and 4G in 2009, but now, 5G is being deployed. Every investment has a certain lifecycle before it is fully amortized. If a new technology appears sooner than the end of this lifecycle, it becomes hard to justify the economic ground of various projects. An example of this is access control in parking lots. Car identification plate recognition and online payments create easy-to-use car parking access systems. However, old token-based in/out barrier lifting devices and cash payments systems are still available many places, as their life cycle is not over yet.

The design of smart cities is, in this way, related to the designers' bet on future technology development.

\section{Noninternet Technologies}

Non-Internet technologies coexist in smart cities with Internet technologies. Most people still use telephones, short messages (called texts or SMS), faxes, letters, etc. To fully reach all citizens, smart cities should include all non-Internet technologies, along with many other technologies such as CCTV, RFID, biometric identification, access cards, etc.

One such device is of particular interest-the public kiosk. A kiosk allows citizens with less digital training to access information regardless of their access to Internet or mobile communications. A surprising number of smart city projects lack kiosks, based on the assumption that all citizens have access to the internet.

Noninteractive street panels also have a role in smart cities. The new technologies allow them to be read in all atmospheric conditions. In too many cities, including smart cities, these are used exclusively for the marketing purposes of the private sector.

Due to the digital divide, many people do not yet have access to digital technologies. A good smart city solution will not avoid this category, and the use of letters (printed and mailed) is considered along with emails and possibly texts (SMS).

\section{Smart Cities and the Digital Divide}

The digital divide plagues the whole world and is largely defined as the gap between people with effective access to digital and information technology and those with very limited or no access at all to the same things, and has many aspects-continents, regions, countries, intracountry: older vs. younger, urban vs. rural, rich vs. poor, educated vs. less educated people, etc., and, of course, cities. Because of the digital divide, a significant part of the population cannot access all of the smart cities' solutions due to a variety of reasons illustrated below. This differs from city to city and country to country. The most affected by this divide are the elderly and poorer segments of the population. Older people are not digital natives; therefore, they have difficulty absorbing new digital technologies. Statistics show an alarming number of older people that have never accessed the Internet. According to Eurostat [9], the percentage of individuals that have never used the Internet in 2018 varies from $4 \%$ in United Kingdom to $27 \%$ in Bulgaria. Romania is listed with $21 \%$, while the average in the European Union (28 countries) is $11 \%$. Among people aged $55-74$, we may see an even less penetration of the Internet [10]. Romania and Bulgaria have about $70 \%$ of people that have never used the Internet. If we add elderly people over 74 years old, the situation is worse, but there are no credible figures for that.

Even though non-Internet applications exist in smart cities, the concept of a smart city is mostly built around Internet and digital communications. The impact of the lack of Internet use by large 
sections of the population is severe, both in the design of new applications, and in the use of existing ones. As shown elsewhere [11,12], bridging the digital divide should be based on four pillars (Figure 3):

1. Appropriate IT infrastructure

2. Accessible and affordable internet access

3. Generalized ability to use IT

4. Availability of useful content

No real digital divide bridge can be built without considering all these four pillars, and no successful smart city project will be successful in the long run.

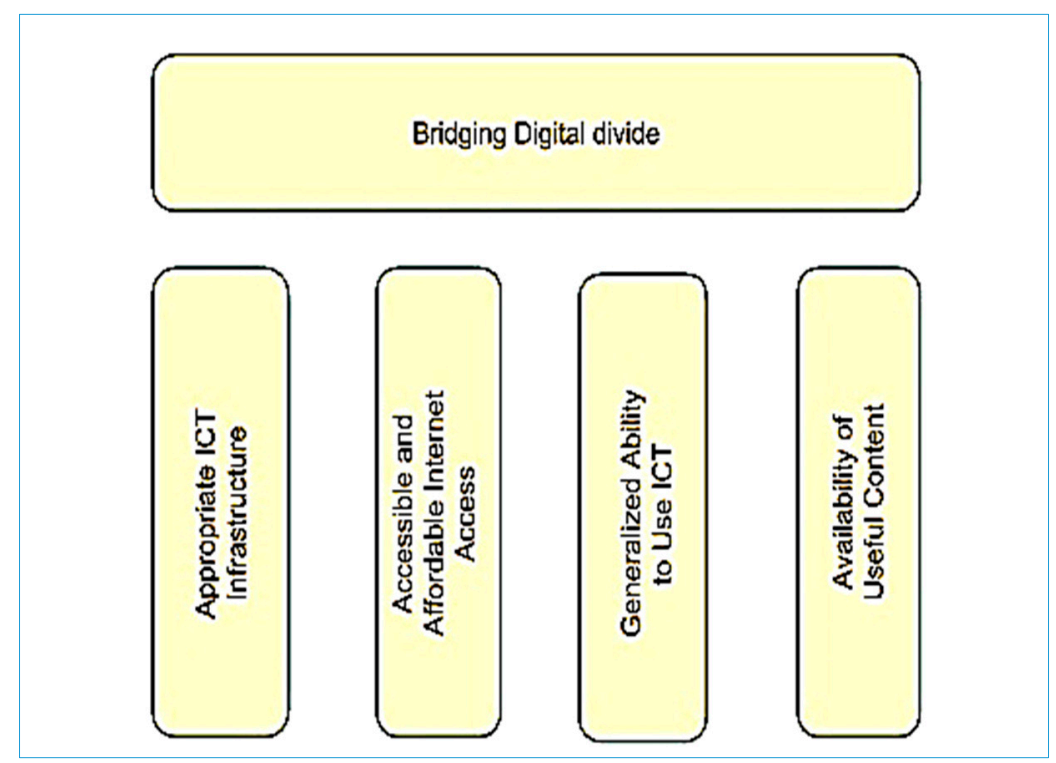

Figure 3. Bridging the Digital Divide.

\subsection{IT Infrastructure}

The role of IT in Internet access is overwhelmingly accepted. A lot of money and effort is spent for infrastructure investments aimed to improve Internet access. While it is important to recognize this effort, one may query if the money is always spent in an optimized manner. The benchmark for a smart city should not be the number of PCs, servers, Wi-Fi access points, etc., but the degree to which they reach the population.

\subsection{Accessible and Affordable Internet Access}

This is probably one of the most critical challenges faced by smart cities projects. Citizens should not only have good smart city architecture and latest technologies but also be able to access them. We mentioned above that a part of the population cannot access the Internet. The elderly are not digital natives and are reluctant to use something they do not understand. There are also other challenges.

The first challenge is affordability. The price paid for access poses a barrier in some cities in relation to the average net earnings of people. Affordability accentuates the divide between rich countries and poorer countries, as the cost of digital services and applications are similar. Most cities have generalized broadband access, and applications are developed for broadband. Despite the trend to use smart devices, many people have cheap mobile devices with no broadband or Internet.

On the other hand, it is true that technology facilitates an increase in the availability and affordability by the continuous price reduction of Internet access and mobile devices. Moore's Law will still be operational for years, and open source software makes applications cheaper.

A smart city has to be for all, and no successful project should be limited to its infrastructure and applications. Provisions for inclusion of all people must be part of the project. As stated above, a smart 
city must be built with smart people. This means that there should not only be investment in education and training, but also proper design considerations to make applications available to poorer, disabled, and older persons.

\subsection{Generalized Ability to Use IT}

People present different levels of abilities to use IT, from pure illiteracy to advanced skills. The level of skills needed depends on the person's job or interest. People from a smart city need skills to access information, products, and services. The level of those skills depends on the level of sophistication of the applications offered. The European Digital Competence Framework for citizens [13] is helping monitor citizen's digital skills and to support curricula development. For a user of smart city applications, digital literacy and sometimes digital awareness levels are enough. Requirement of a high level would put a question mark on the efficiency of the application. An example for an appropriate level of skills is the eCitizen program from the same ECDL Foundation [14]. Such a program enables people to learn how to use computers and the Internet and provides essential skills that people need to actively access and engage in the information society - in this case, in a smart city.

The staff of city officers in charge of maintenance and updating of smart city applications should have adequate digital competence. In practice, quite often, they do not have the necessary level of competence, and this leads to failures of many smart city initiatives.

The smart city concept is therefore strongly linked to eInclusion or Digital inclusion. There have been several studies regarding various forms of digital education in smart city initiatives $[15,16]$.

\subsection{Availability of Useful Content}

Content is in the core of smart city initiatives. People look for what they need and what is appropriate. In general, the content on the Internet is generally free, but is often also paid for. In smart city applications, the content should always be free. The variety of content is one of the features of a good smart city project.

It is essential that the content is available on all types of devices used by the population of the city in all languages required [17]. If the city has a touristic appeal, foreign language content is a must. On the other hand, it would be a mistake to have content only in foreign languages, omitting the language(s) of the native citizens. An example would be the application of car park payment via one's mobile phone, technology that is already in place in many cities. If the instructions are only in the native language and they use a non-Latin alphabet, a visitor unable to read and understand that language will have serious difficulties.

It is true that technology helps. Google Translate now has a feature that enables reading text in many languages and alphabets, but it is still in the beta phase, and a smart city project should not rely on newer apps, considering how many people do not use them.

Content must be constantly updated to provide correct information. In many cases, the information offered by many city offices is old and obsolete $[18,19]$.

\section{Smart Cities-Acceleration and Deceleration Factors}

Like any other breakthrough innovation, the implementation of smart cities projects is accelerated or decelerated by several factors.

The most important acceleration factor is the digital technology itself. New and new digital disruption technologies appear at an accelerating pace. Many important tools and apps for smart city implementations are less than 12 years old. The growth of cities and the increasing number of people living in them call for solutions for a better life and the smart cities concept is certainly one of these solutions. The public opinion is favorable to new projects, either big or small.

However, there are many deceleration factors that lead to the slow development and sometimes failure of projects. 
Cities are, in most cases, already existent, and their development is a result of decades or centuries of city planning or a lack of sufficient planning.

City planners can be reluctant, but citizens may also show some reservations about some of the changes in the city landscape or installation of some equipment. This is true in the case of antennas, street cables, cameras, etc. There is an increasing fear of radiation of Wi-Fi and mobile operators' antennas and concerns [20,21], and about security and privacy [22-24].

An adverse effect is due to the abovementioned digital divide, especially the lack of digital competencies and understanding of the digital world. Most managers and decision-makers are in their 50 s or 60 s and are not digitally savvy [11,12]. A delay of smart city projects or even opposition to them is probable. It is not an accident that a city as large as Bucharest does not have a smart city strategy yet [7]; such a study was commissioned only in 2018 [25].

Citizens' lack of digital competence is a major obstacle in smart city projects based on IT. We may also encounter a lack of project goal understanding from designers. They are attracted by the latest technology achievements and ignore the fact that the population is not prepared to use them. The decision-makers are not always adequately digitally competent, and often approve projects only because they are fashionable.

\section{Smart City—A Fashionable Topic or a Necessity}

The lack of strategies does not mean that many cities do not report a lot of smart city projects. Some of them are of less importance and others become obsolete before their implementation. Money is spent because the smart city is a political priority and is fashionable. An application that shows when your bus is scheduled to arrive is completely useless in a city where traffic is out of control during rush hours. An online tax payment system was implemented in Romania in 2002 in an environment where very few people had cards or digital competence [26]. The impact was insignificant.

The lack of vision does not mean that many events are not organized, and an impressive list of projects has been reported. This has a role in public education, but the real approach should be a strategy, a master plan for step-by-step implementation of smart city initiatives.

The internet and smart mobiles proliferate quickly. Currently, $57.3 \%$ of world population uses the Internet, with North America (89.4\%) and Europe (86.8\%) having the highest percentages [27]. In Europe, the latest reports show that basic broadband is available in all homes in the EU when considering all major technologies (xDSL, cable, fiber to the premises-FTTP, WiMax, HSPA, LTE, and satellite); moreover, fixed and fixed wireless technologies cover $97 \%$ of EU homes [28]. We may safely assume that figures are higher for cities. However, there is a large discrepancy among cities of different countries and even within the same country.

A recent (2019) example in Romania illustrates the lack of infrastructure, the smartphone vs. mobile phone divide, and both the government's and citizens' approach to problems. A call to emergency services 112 by a person in distress could not be localized due to a rudimentary location service of the 112-system that is based only on the mobile operator's triangulation. The victim died. The absence of AML (advance mobile location), a facility that makes the location of the caller available to emergency call takers in real-time, became a topic of debate. However, AML responds to the smartphones only from certain manufacturers.

The penetration of smartphones has become a critical acceleration or deceleration factor. People use their mobile devices more frequently than desktops. Still, there is a divide between Western Europe and the USA and other countries [29].

\section{Measuring Performance and Benchmarking}

The interest in the concept of the smart city is real, and more and more projects are being proposed and implemented. Part of the reason is the worsening of city problems (traffic, pollution, rapid expansion, etc.) and the hope that a smart city is a panacea to all these problems. Measuring the 
performance of smart city implementation and continuous benchmarking are necessary tools, and many such models have been proposed [3,30].

Smart cities are sought by people to improve their lives and by governments to respond to these expectations and optimize their investments. The rankings of cities based on various criteria are frequently published. Most ratings and benchmarks are based on the five smart city dimensions-smart governance, smart mobility, smart environment, smart people, and smart living. Figure 4 shows the ratings of three European cities when compared to an average of all the cities in the study [31].

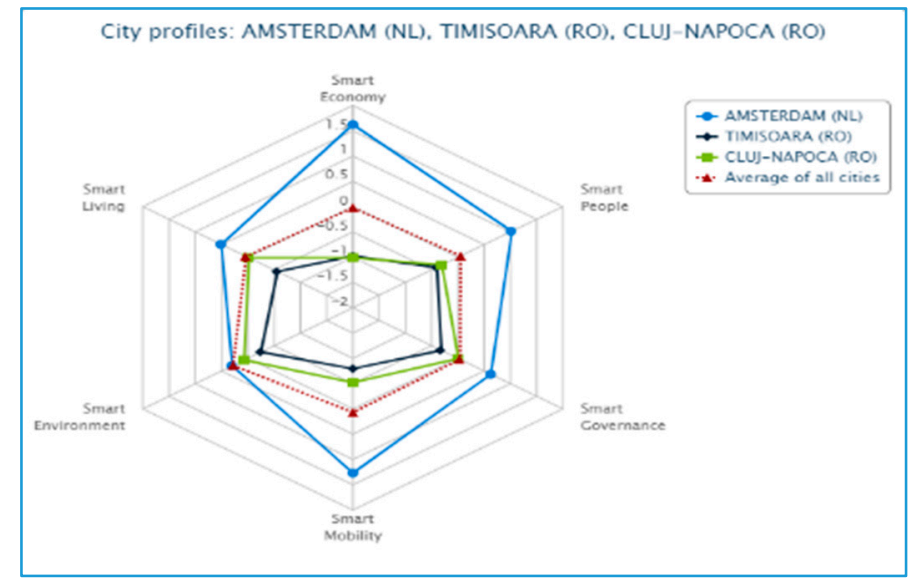

Figure 4. Smart city benchmark. Source data: Vienna University.

Other authors go further to nine main dimensions, which are human capital, social cohesion, the economy, public management, governance, the environment, mobility and transportation, urban planning, international outreach, and technology [32] or even more [33]. Various approaches lead to contradictory rankings, as seen in Table 1.

Table 1. Smart Cities Ranking 2019.

\begin{tabular}{lcc}
\hline & Ranking [32] & Ranking [33] \\
\hline 1 & London & London \\
2 & New York & Singapore \\
3 & Amsterdam & Barcelona \\
4 & Paris & Amsterdam \\
5 & Reykjavik & Boston \\
6 & Tokyo & New York \\
7 & Singapore & Hong Kong \\
8 & Copenhagen & Chicago \\
9 & Berlin & Delhi \\
10 & Vienna & Paris \\
\hline
\end{tabular}

Complex criteria are not always taken into consideration. There are rankings based on the number of projects $[34,35]$. Projects can have bigger or lesser impact, and simply counting them has no major relevance.

It is difficult to accept a unified ranking mix, but the major features of a smart city are measured and updated frequently, in many cases, by academic studies. The most convenient approach would be to compile comprehensive rankings by an international organization based on reputable reports and statistics. The United Nation does it for eGovernment [36] and the European Union for Digital Society [37]. 


\section{Conclusions}

The concept of the smart city is mostly related to the use of digital technologies in all city functions. A smart city should be defined less based on the IT solutions implemented and the number of digital devices used, but more on the optimization of its functions.

There are many challenging societal aspects related to this concept [38]. The smart city concept inherits many of the challenges of early eGovernment implementations-lack of planning and wastage of resources. This is frequently the case when the digital divide is a concern, from the perspective of both citizens and city administration staff. Smart city projects are the result of the fourth industrial revolution, the cyber physical revolution. However, many cities still lack a full implementation of solutions of the previous industrial revolutions, mainly regarding city planning and transportation networks.

There is currently a lot of interest around the smart city concept. Many cities around the world report smart city projects; however, some of them are of less importance, while others become obsolete before their implementation. In some cases, money is spent simply because smart cities are a political priority and are considered fashionable.

The smart city concept is closely related to digital technology. Several aspects of digital technology use in smart cities raise concerns. One is the lack of adaptation of city structures to the potential of new technologies. Another is the lack of general restructuring of the city before the implementation of smart city solutions. Applying IoT and other advanced digital technology solutions to old, not updated, urban structures reduces the efficiency of smart city implementations. Non-Internet technologies coexist with Internet technologies in smart cities. Many people do not yet have access to digital technologies.

A good smart city solution will take onto account the real environment of the city and will not avoid using older digital and nondigital technologies.

Many smart cities are affected by the digital divide. A full implementation of the concept of smart city requires a bridging of the digital divide based on the four pillars mentioned above-appropriate IT Infrastructure, accessible and affordable Internet access, generalized ability to use IT, and availability of useful content.

The implementation of smart city projects is accelerated and decelerated by various factors. The most important acceleration factor is the digital technology itself, as new disrupting digital technologies appear at an accelerating rate. City planners can be reluctant, and citizens may also show some reservations. Other deceleration factors also exist-the fear of radiation from various devices and concerns about security and privacy. To that, we can also add low broadband and smart mobile device penetration. Citizens' lack of digital competence is a major obstacle in smart city projects, and a lack of ultimate goal understanding from designers affects the projects.

Accurate evaluation smart city implementations is important. Rankings of cities based on several criteria are frequently published. Various approaches lead to contradictory rankings. A new set of comprehensive rankings developed by an international organization and based on reputable reports and statistics is necessary.

Funding: This research received no external funding.

Conflicts of Interest: The author declares no conflict of interest.

\section{References}

1. Schwab, K. The Fourth Industrial Revolution; Currency, The Crown Publishing Group: London, UK, 2017.

2. Smart City. Available online: https://en.wikipedia.org/wiki/Smart_city (accessed on 4 December 2019).

3. City of Vienna. "Smart City Wien Framework Strategy Overview." Smart City Wien. July 2014. Available online: https://smartcity.wien.gv.at/site/files/2014/10/140924_KF_SCW_gesamt_ENG.pdf (accessed on 4 December 2019).

4. Perez, C. Technological Revolutions and Financial Capital: The Dynamics of Bubbles and Golden Ages; EdwardEdgar Publishing: Cheltenham, UK, 2002. 
5. Ponting, A. High-Tech Urbanism The Political and Economic Implications of the Smart City Honors Thesis Program on Urban Studies Stanford University. Urban Studies Stanford University. 13 May 2013. Available online: https://urbanstudies.stanford.edu/sites/default/files/ponting-finalthesis.pdf (accessed on 4 December 2019).

6. Google Scholar Search for Smart City. Available online: https://scholar.google.com/scholar?hl=en\&as_sdt= $0 \% 2 \mathrm{C} 5 \& \mathrm{q}=$ smart+city\&btnG $=$ (accessed on 4 December 2019).

7. Baltac, V. Orașul Inteligent și Decalajele Digitale (Smart City and Digital Divide), SNSPA Smart City Conference Third Edition 2016, Bucharest. Available online: http://www.administratiepublica.eu/ smartcitiesconference/publicatii/Orasul_inteligent_editia_03.pdf (accessed on 4 December 2019).

8. Mehrotra, K. San Francisco Bans City Use of Facial Recognition Technology Tools. Los Angeles Times. 14 May 2019. Available online: https://www.latimes.com/business/la-fi-san-francisco-facial-recognition-ban20190514-story.html (accessed on 4 December 2019).

9. Eurostat. Individuals Who Have Never Used the Internet. Available online: https://ec.europa.eu/eurostat/ databrowser/bookmark/be952c0c-e832-4c50-8a9a-e76787bc906a?lang=en (accessed on 4 December 2019).

10. European Parliamentary Research Service Blog. 55-74 Years Old Who Have Never Used the Internet in 2014 by Country. Available online: https://epthinktank.eu/2015/12/15/bridging-the-digital-divide-in-the-eu/55-74years-old-who-have-never-used-the-internet-in-2014-by-country/ (accessed on 4 December 2019).

11. Baltac, V. South Eastern Europe: Digital Divide or Digital Opportunity? In Proceedings of the "Information Science and Technology" Conference-IST 2000, Nice, France, 6-8 November 2000. Available online: https://www.researchgate.net/publication/268416706_South_Eastern_Europe_Digital_Divide_or_ Digital_Opportunity (accessed on 4 December 2019).

12. Baltac, V. Education and the Second Generation Digital Divide. Presented at the 4th IT STAR Workshop on ICT Skills, Education and Certification: The Multistakeholders Partnership, Rome, Italy, 27-28 November 2009. Available online: https://www.academia.edu/11617644/Education_and_the_Second_Generation_Digital_ Divide (accessed on 4 December 2019).

13. EU SCIENCE HUB DIGCOMP. The Digital Competence Framework for citizens. Available online: https://ec.europa.eu/jrc/en/digcomp (accessed on 4 December 2019).

14. ECDL Foundation, e-Citizen. Available online: http://ecdl.org/about-ecdl/e-citizen (accessed on 4 December 2019).

15. Wiig, A. The empty rhetoric of the smart city: From digital inclusion to economic promotion in Philadelphia. Urban Geogr. 2016, 37, 535-553. Available online: https://www.tandfonline.com/doi/full/10.1080/02723638. 2015.1065686 (accessed on 4 December 2019). [CrossRef]

16. Nam, T.; Pardo, T.A. Conceptualizing Smart City with Dimensions of Technology, People, and Institutions. In Proceedings of the 12th Annual International Conference on Digital Government Research, DG.O 2011, College Park, MD, USA, 12-15 June 2011. Available online: https:/smartcitiescouncil.com/sites/default/files/ public_resources/Conceptualizing\%20smart\%20city.pdf (accessed on 4 December 2019).

17. Gobbi, A.; Stefania, S. Smart Cities and Languages: The Language Network. IxDEA 2013, 16, 37-46. Available online: https://www.researchgate.net/publication/271589413_Smart_Cities_and_Languages_The_ Language_Network (accessed on 4 December 2019).

18. Vrabie, C. E-Guvernarea în Municipiile României Studiu 2015 (E-Government in Municipalities of Romania Study 2015), Pro-Universitaria 2015. Available online: https://www.researchgate.net/publication/280559400_ E-Guvernarea_in_municipiile_Romaniei_-_Studiu_de_impact_Nr_22014 (accessed on 4 December 2019).

19. Baltac, V. Lumea Digitală—Concepte Esențiale (Digital World—Basic Concepts); EXCEL XXI Books Publishing House: Bucharest, Romania, 2015; p. 205.

20. Wisz, J. Potential Hazards of Cellular Phone Radiation: Responses to Fear and Uncertainty. Available online: https://dash.harvard.edu/bitstream/handle/1/8889484/Wisz.pdf?sequence=1 (accessed on 4 December 2019).

21. Havas, M. Radiation from wireless technology affects the blood, the heart, and the autonomic nervous system. Presented at the Corporate Interference with Science and Health: Fracking, Food, and Wireless, Scandinavia House, New York, NY, USA, 13-14 March 2013. Available online: https://ecfsapi.fcc.gov/file/7520958029.pdf (accessed on 4 December 2019).

22. Van Zoonen, L. Privacy concerns in smart cities. Gov. Inf. Q. 2016, 33, 472-480. Available online: https:/www.sciencedirect.com/science/article/pii/S0740624X16300818?via\%3Dihub (accessed on 4 December 2019). [CrossRef] 
23. Zhang, K.; Ni, J.; Yang, K.; Liang, X.; Ren, J.; Shen, X.S. Security and Privacy in Smart City Applications: Challenges and Solutions. IEEE Commun. Mag. 2017, 55, 122-129. Available online: https://www.researchgate.net/ publication/312576686_Security_and_Privacy_in_Smart_City_Applications_Challenges_and_Solutions (accessed on 4 December 2019). [CrossRef]

24. Ati, M.; Basmaji, T. Framework for Managing Smart Cities Security and Privacy Applications. In Proceedings of the IEEE Symposium on Computer Applications and Industry Electronics, Penang, Malaysia, 28-29 April 2018. Available online: https://www.researchgate.net/publication/324899608_Framework_ for_Managing_Smart_Cities_Security_and_Privacy_Applications (accessed on 4 December 2019).

25. Bucharest Mayor Signs Contract with Deloitte for Drafting Smart City Strategy. Romania Insider. 26 July 2018. Available online: https://www.romania-insider.com/bucharest-deloitte-smart-city-strategy (accessed on 4 December 2019).

26. Baltac, V. E-Guvernarea-Moda sau Necesitate? (eGovernment-Fashion or Necessity) in Mituri si Realitate in Lumea Digitala (Myths and Reality in Digital World); EXCEL XXI Books Publishing House: Bucharest, Romania, 2017.

27. Internet World Stats Internet Penetration by Geographical Regions. Available online: https://www. internetworldstats.com/stats.htm (accessed on 4 December 2019).

28. European Union Connectivity Broadband Market Developments in the EU. Digital Economy and Society Index Report 2019 Connectivity. Available online: https:/ec.europa.eu/digital-single-market/en/connectivity (accessed on 4 December 2019).

29. Newzoo Top 50 Countries/Markets by Smartphone Users and Penetration. Available online: https://newzoo. com/insights/rankings/top-50-countries-by-smartphone-penetration-and-users/ (accessed on 4 December 2019).

30. Anthopoulos, L.; Janssen, M.; Weerakkody, V. A Unified Smart City Model (USCM) for Smart City Conceptualization and Benchmarking, IGI Global. Available online: https:/www.igi-global.com/chapter/aunified-smart-city-model-uscm-for-smart-city-conceptualization-and-benchmarking/211294 (accessed on 4 December 2019).

31. Technische Universtaet Wien. European Smart Cities. Available online: http://www.smart-cities.eu/ (accessed on 4 December 2019).

32. IESE Business School. IESE Cities in Motion Index 2019. Available online: https://blog.iese.edu/citieschallenges-and-management/2019/05/10/iese-cities-in-motion-index-2019/ (accessed on 4 December 2019).

33. Joss, S.; Sengers, F.; Schraven, D.; Caprotti, F.; Dayot, Y. The Smart City as Global Discourse: Storylines and Critical Junctures across 27 Cities. J. Urb. Technol. 2019, 26, 3-34. Available online: https://www.tandfonline. com/doi/full/10.1080/10630732.2018.1558387 (accessed on 4 December 2019). [CrossRef]

34. ARSCM. Alba Iulia-Leading City in Romania according to the Number of Smart City Projects. Available online: http://www.energynomics.ro/en/alba-iulia-leading-city-in-romania-according-to-the-number-ofsmart-city-projects/ (accessed on 4 December 2019).

35. Barbut, C. Scanning Smart Cities of Romania Report-Second edition. Available online: https://vegacomp. ro/scanning-smart-cities-of-romania-report-second-edition/ (accessed on 4 December 2019).

36. UN. E-Government Knowledge Data Base. Available online: https://publicadministration.un.org/egovkb/enus/Reports/UN-E-Government-Survey-2018 (accessed on 4 December 2019).

37. European Commission. The Digital Economy and Society Index (DESI). Available online: https:/ec.europa. eu/digital-single-market/en/desi (accessed on 4 December 2019).

38. Ribeiro, S.S. Issues of Strategic Digital City. Urb. Sci. 2019, 3, 102. [CrossRef]

(C) 2019 by the author. Licensee MDPI, Basel, Switzerland. This article is an open access article distributed under the terms and conditions of the Creative Commons Attribution (CC BY) license (http://creativecommons.org/licenses/by/4.0/). 